\title{
Gestão de resíduos sólidos na zona urbana do Município de Varzelândia, Minas Gerais, Brasil: um olhar pela via da gestão municipal e impressões da população
}

\section{Neucy Teixeira Queiroz ${ }^{1}$, Eloir Trindade Vasques Vieira ${ }^{2}$}

\author{
${ }^{1}$ Universidade Federal do Vale do Jequitinhonha e Mucuri. Campus JK. Rodovia \\ MGT-367, km 583, 5000. Alto da Jacuba. Diamantina-MG, Brasil (CEP \\ 39100-000) E-mail: neucyqueiroz@yahoo.com.br. \\ 2Universidade Católica Dom Bosco. Reitoria. Coordenação de Curso. Av Tamandaré, \\ 6000, Jardim Seminário. Campo Grande-MS, Brasil (CEP 79117-900). E-mail: \\ eloir@ucdb.br.
}

Resumo. Este trabalho teve como objetivo analisar a gestão de resíduos sólidos urbanos (RSU) na zona urbana do município de Varzelândia, Minas Gerais, Brasil, do ponto de vista da população e do gestor municipal e analisar se esta gestão atende aos princípios da Política Nacional dos Resíduos Sólidos (PNRS). Para realização do trabalho foi utilizada a metodologia da amostragem intencional sendo empregada a análise estatística descritiva para comparar os dados coletados. Os resultados demonstraram que $97,0 \%$ da população afirmam ter coleta de resíduos sólidos no município, entretanto, houve reclamações nesse tipo de serviço, onde dos entrevistados, $17,0 \%$ reclamaram da coleta em poucos dias, $8,5 \%$ reclamaram do resíduo sólido exposto por muito tempo e 8,5\% reclamaram da demora na coleta. Assim, é possível concluir que a população está satisfeita com a gestão dos resíduos sólidos, apesar de essa gestão não obedecer alguns quesitos da PNRS.

Palavras-chave: Resíduos sólidos; Sustentabilidade; Expansão demográfica; Gestão ambiental.

Abstract. Solid waste management in the urban area of the municipality of Varzelândia, Minas Gerais State, Brazil: a look through the municipal management and impressions of the population. This study aimed to analyze the solid waste management (RSU) in the urban area of the municipality of Varzelândia, Minas Gerais State, Brazil, from the point of view of the population and municipal manager and investigate if this management complies with the principles of the National Policy of Solid Waste (PNRS). The intentional sampling method was applied, and the descriptive statistical analysis was used to compare the data collected. The results showed that $97.0 \%$ of the population stated there is garbage collection in the municipality. However, some of the interviewees complained about the service:
Recebido:

$03 / 03 / 2018$

Aceito:

$27 / 04 / 2018$

Publicado:

$30 / 04 / 2018$

Acesso aberto

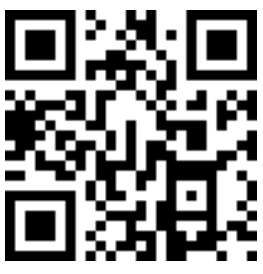

ORCID

(ㄷ) 0000-0002-7387-1566 Neucy Teixeira Queiroz

(D) 0000-0002-6587-4599 Eloir Trindade

Vasques Vieira 
$17.0 \%$ said there are few days of collection, $8.5 \%$ complained about the trash exposed for a long time, and $8.5 \%$ complained about the delay in collection. Thus, it is possible to conclude that the population is satisfied with the solid waste management, although this management does not comply with some requirements of the PNRS.

Keywords: Solid wastes; Sustainability; Demographic expansion; Environmental management.

\section{Introdução}

Nos últimos tempos as cidades têm se desenvolvido bastante e, consequentemente, houve o aumento da população nos centros urbanos, gerando maior consumo de bens, serviços e produtos diversificados no mercado, sendo este consumo, muitas vezes, excessivo, emergindo assim uma nova era, "a era do consumismo". Esse consumismo reflete diretamente na quantidade de resíduos sólidos que é produzida, uma vez que as pessoas simplesmente substituem seus produtos descartando os antigos, contribuindo para o aumento gradativo da produção dos Resíduos Sólidos Urbanos (RSU).

E este aumento, tem sido motivo de grande preocupação, principalmente nas grandes cidades por falta de espaço para a deposição dos RSU.

Além do problema da falta de espaço, existe o do manejo inadequado dos resíduos sólidos que pode provocar problemas de saúde à população através da proliferação de vetores de doenças, como roedores e insetos e odores desagradáveis. Ademais, a destinação e o tratamento inapropriados do resíduo sólido podem provocar problemas ambientais, através da poluição do solo, ar e água, sendo necessário um plano de manejo dos RSU.

Segundo Jacobi e Besen (2011), o gerenciamento dos resíduos sólidos, desde a coleta até a deposição final é responsabilidade da administração pública municipal. Sendo assim, o trabalho tem como objetivo verificar como ocorre a gestão de resíduos sólidos na zona urbana do município de
Varzelândia do ponto de vista do gestor e da população e verificar se a mesma atende aos princípios e objetivos da Política Nacional de Resíduos Sólidos (PNRS), pois, o município está de desenvolvendo sendo importante essa análise.

\section{Resíduos sólidos}

A expansão demográfica tem sido associada ao aumento da produção de resíduos no planeta, pois quanto mais pessoas, maior será o consumo, a produção de alimentos, o aumento do número de construções; e todos esses itens geram resíduos que são descartados na forma de resíduos sólidos.

Zveibil (2001) classifica "resíduo sólido ou lixo" como "todo material sólido ou semissólido indesejável e que necessita ser removido por ter sido considerado inútil por quem o descarta em qualquer recipiente destinado a este ato".

Quanto à definição de Zveibil (2011), cabe aqui uma ressalva, pois, nem tudo que é descartado nas casas pode ser considerado inútil, visto que muitos materiais podem ser recicláveis e o processo de reciclagem vem trazer utilidade a determinados produtos, além de contribuir para a redução de resíduos sólidos.

Godecke et al. (2012) relacionam a questão demográfica com aspectos econômicos e culturais, associando a quantidade de resíduos sólidos produzidos aos níveis de riqueza, poder de consumo e relacionam também ao estilo de vida da população, considerando os aspectos supracitados 
como requisitos para a disposição para o consumo.

Devido ao aumento da produção, e o sequente consumismo, houve aumento gradual na quantidade de resíduos sólidos gerados. Nesse contexto podemos exemplificar os principais RSU os quais podem aumentar a sua produção com o aumento populacional que são os resíduos sólidos de construção civil, os industriais e dos serviços de saúde. Neste trabalho será dada ênfase à gestão dos RSU. Sobre a gestão dos resíduos sólidos, Russo (2003), destaca:

A gestão de resíduos sólidos pode ser definida como uma disciplina associada ao controle, produção, armazenamento, recolha, transferência e transporte, processamento, tratamento e destino final dos resíduos sólidos, de acordo com os melhores princípios de preservação da saúde pública, economia, engenharia, conservação dos recursos, estética e outros princípios ambientais (Russo, 2013: 8).

A gestão ambiental apropriada dos resíduos sólidos traz aspectos benéficos à sociedade e ao meio ambiente, proporcionando saúde e bemestar além de uma paisagem apreciativa.

\section{Gestão ambiental}

A gestão ambiental segue alguns princípios e leis que regulamentam a gestão dos RSU, contribuindo para a qualidade de vida da população e dos recursos naturais. Entretanto, com a expansão demográfica, essa gestão tem se tornado um desafio à medida que as cidades de desenvolvem.

0 rápido crescimento populacional tem sido motivo de preocupação, pois paralelamente, ao aumento na produção de RSU, há existência de problemas socioambientais, como poluição do meio ambiente e proliferação de vetores de doenças. A gestão ambiental vem trazendo as políticas necessárias para manter o desenvolvimento susten- tável, trazendo equilíbrio entre desenvolvimento/sociedade e natureza.

\section{Sólidos}

\section{Política Nacional dos Resíduos}

Uma administração que proporcione o desenvolvimento sustentável na gestão dos resíduos sólidos deve levar em conta alguns aspectos estabelecidos na legislação e compreender algumas leis preestabelecidas.

A Lei no 12.305/2010, institui a Política Nacional de Resíduos Sólidos (PNRS) que dispõe sobre "seus princípios, objetivos e instrumentos, bem como sobre as diretrizes relativas à gestão integrada e ao gerenciamento de resíduos sólidos, incluídos os perigosos, às responsabilidades dos geradores e do poder público e aos instrumentos econômicos aplicáveis (Brasil, 2012).

Em seu art. 4ํㅜ a Política Nacional de Resíduos Sólidos diz que ela

reúne o conjunto de princípios, objetivos, instrumentos, diretrizes, metas e ações adotadas pelo governo federal, isoladamente ou em regime de cooperação com estados, Distrito Federal, municípios ou particulares, com vistas à gestão integrada e ao gerenciamento ambientalmente adequado dos resíduos sólidos (Brasil, 2012).

Este art. 4ำ tem sido um aparato ao meio ambiente, uma vez que não é possível desenvolvimento sem a preocupação ambiental, pois a sociedade é dependente da natureza, principalmente no que se refere à qualidade do ar, solo e água. Sendo assim, o gerenciamento ambientalmente adequado dos resíduos sólidos proporciona uma segurança à população, no que se refere à qualidade de vida da população e atendimento aos princípios ambientais.

Ainda sobre a Lei $\mathrm{n}^{\circ}$ $12.305 / 2010$, em seu art. $7^{\circ}$, dentre os seus objetivos, destaca os seguintes, que são essenciais ao controle socioambiental: 
qualidade ambiental;

I - proteção da saúde pública e da

II - não geração, redução, reutilização, reciclagem e tratamento dos resíduos sólidos, bem como disposição final ambientalmente adequada dos rejeitos;

III - estímulo à adoção de padrões sustentáveis de produção e consumo de bens e serviços;

IV - adoção, desenvolvimento e aprimoramento de tecnologias limpas como forma de minimizar impactos ambientais;

$\mathrm{V}$ - redução do volume e da periculosidade dos resíduos perigosos;

VI - incentivo à indústria da reciclagem, tendo em vista fomentar o uso de matérias-primas e insumos derivados de materiais recicláveis e reciclados;

VII - gestão integrada de resíduos sólidos;

Sobre esses objetivos, todos têm uma grande importância no contexto dos resíduos sólidos. Cabe uma grande ênfase aos itens II, III e VI que tratam da não geração/redução, padrões sustentáveis de consumo e incentivo a reciclagem, respectivamente; pois a reciclagem é um fator fundamental para reduzir a qualidade de resíduo sólido e reduzir a poluição ao meio ambiente, principalmente a poluição do solo e aquática. Além disso, a reciclagem pode ser uma fonte de renda para as pessoas, até mesmo para grandes empresas que reutilizam suas embalagens ao invés de produzir novas, o que geraria gastos de energia e matéria-prima; além de ajudar na melhoria da limpeza da cidade.

Sendo assim, a própria população pode contribuir para melhorar a gestão de resíduos sólidos, pois, a não geração ou redução de resíduos sólidos depende da colaboração da sociedade.

\section{Ambiente}

\section{Política Nacional do Meio}

A Lei no 6.938/1981 (Brasil, 2011), dispõe sobre a Política Nacional do Meio Ambiente. Seu art. $2^{\circ}$, diz que "a
Política Nacional do Meio Ambiente (PNMA) tem por objetivo preservação, melhoria e recuperação da qualidade ambiental propícia à vida, visando assegurar, no país, condições ao desenvolvimento socioeconômico, aos interesses da segurança nacional e à proteção da dignidade da vida humana." A PNMA ampara os seguintes princípios:

I - ação governamental na manutenção do equilíbrio ecológico, considerando o meio ambiente como um patrimônio público a ser necessariamente assegurado e protegido, tendo em vista o uso coletivo;

II - racionalização do uso do solo, do subsolo, da água e do ar;

III - planejamento e fiscalização do uso dos recursos ambientais;

IV - proteção dos ecossistemas, com a preservação de áreas representativas;

$\mathrm{V}$ - controle e zoneamento das atividades potencial ou efetivamente poluidoras;

VI - incentivos ao estudo e à pesquisa de tecnologias orientadas para o uso racional e a proteção dos recursos ambientais;

VII - acompanhamento do estado da qualidade ambiental;

VIII - recuperação de áreas degradadas;

IX - proteção de áreas ameaçadas de degradação;

$X$ - educação ambiental a todos os níveis de ensino, inclusive a educação da comunidade, objetivando capacitá-la para participação ativa na defesa do meio ambiente.

Todos esses princípios são importantes para um desenvolvimento equilibrado entre sociedade e meio ambiente. Entretanto, muitas vezes, algumas pessoas não compreendem a importância dessa preocupação com os recursos naturais e com a recuperação de eventuais danos causados pelo manejo inadequado dos resíduos sólidos urbanos, por isso, a educação ambiental vem sendo um princípio importante para prestar maiores esclarecimentos à 
população e deve ser um ponto relevante no processo de gestão dos resíduos sólidos urbanos.

\section{Resíduos sólidos e a questão socioambiental}

No desenvolvimento urbano, que é acompanhado pelo crescimento populacional, o manejo integrado dos resíduos sólidos deve ser feito de forma planejada e a PNRS tem sido uma fonte de orientação para esse planejamento.

0 tratamento ou deposição inadequada dos RSU pode provocar poluição das águas, através da destinação imprópria; do solo, através de determinados materiais como chumbo, mercúrio e do ar através da liberação de gases poluentes provenientes da queima dos resíduos sólidos, por exemplo. Por isso, não se recomenda a queima/incineração. A não ser que não haja outra opção que se possa aderir. Apesar de não muito recomendada a incineração, Barros (2013) mostra que a incineração diminui de maneira significativa a quantidade de resíduo sólido, constituindo isso uma vantagem desse processo.

"A geração crescente de resíduos sólidos nos aglomerados urbanos constitui um grave problema socioambiental, que resulta dos padrões atuais insustentáveis de produção e consumo, e que provoca impactos ambientais e de saúde pública que precisam ser enfrentados" (Jacobi e Besen, 2006).

Sendo assim, o manejo adequado dos resíduos sólidos gera contribuições socioambientais positivas, pois ajuda a melhorar a qualidade do meio ambiente e consequentemente a qualidade de vida da população.

\section{Resíduos sólidos e o desenvolvimento sustentável \\ 0 conceito de desenvolvimento} sustentável não é muito antigo. Foi definido no relatório de Bruntland, divulgado pela Comissão Mundial Sobre Meio Ambiente e Desenvolvimento (CMMAD, 1991) que o definiu como "aquele que permite satisfazer as necessidades do presente sem comprometer as possibilidades das gerações futuras satisfazerem as suas".

Neste sentido, em se tratando do manejo integrado dos resíduos sólidos, podemos considerar a conservação da natureza e ocupação e uso adequados do solo como requisitos para o desenvolvimento sustentável, além do uso dos princípios da PNRS e da PNMA.

A preocupação com a poluição do ar, dos recursos hídricos do subsolo é essencial. Sendo assim, nos planos de gestão dos RSU é preciso haver medidas que minimizem os impactos ambientais, para tal fim é necessário monitoramento em todas as fases do processo de tratamento do lixo. Nogueira et al. (2007) enfatizam a importância do monitoramento em aterros sanitários: "A necessidade de monitoramento da operação dos aterros sanitários constitui-se uma exigência explícita na legislação ambiental brasileira e das normas técnicas conhecidas."

Além do monitoramento da qualidade ambiental e dos serviços de RSU, a harmonia entre potencial produtivo e crescimento populacional. "A busca pelo desenvolvimento sustentável só é possível se o tamanho e o crescimento da população estiverem em harmonia com 0 potencial produtivo do ecossistema" (Bartholomeu e Caixeta-Filho, 2011).

Sobre o potencial produtivo e o aumento populacional os autores Bartholomeu e Caixeta-Filho (2011), ainda concluem que "um rápido crescimento populacional pode de fato, retardar qualquer melhoria nos padrões de vida, dada a limitação e a pressão sobre os recursos".

Processos de reciclagem e aproveitamentos energéticos podem representar fatores capazes de contribuir para o desenvolvimento sustentável.

\section{urbanos}

Reciclagem de resíduos sólidos

Uma das medidas possíveis de serem tomadas para a redução do resíduo sólido é a reciclagem. Vários 
materiais podem ser reutilizados gerando emprego, renda e economia à população, contribuindo também para a economia de materiais e energia por empresas. É atribuído valor aquilo que teoricamente seria resíduo sólido.

"Uma vez gerados, os resíduos sólidos não deixam, necessariamente, de possuir valor. Parte significativa deles pode ser reutilizada, recuperada ou reciclada para uso na própria indústria ou externamente, de forma a reintegrá-lo ao ciclo econômico" (Bartholomeu e Caixeta-Filho, 2011, p. 118).

A reciclagem é de extrema importância na gestão de resíduos sólidos, devendo ser uma preocupação no gerenciamento dos resíduos sólidos.

\section{Aproveitamento Energético dos Resíduos sólidos}

A busca por fontes alternativas de energia tem sido um fator importante na sociedade atual, pois boa parte da energia é proveniente dos recursos hídricos e os mesmos vêm se esgotando com o decorrer do tempo, devido aos longos períodos de estiagem. Os resíduos sólidos tem se constituído como uma opção de aproveitamento energético.

"Estudos de prospecção feitos pela Agência Internacional de Energia (IEA, 1997) apresentam a evolução da disponibilidade de resíduos sólidos para uso em incineradores objetivando a geração de energia elétrica" (Henriques, 2004).

"O aproveitamento energético de resíduos sólidos constitui uma alternativa promissora, representando um elemento importante de uma estratégia de ampliação da geração de energia, diversificação da matriz energética e utilização das fontes alternativas de energia" (Bartholomeu e Caixeta Filho, 2011, p. 120).

De acordo Henriques (2004), no Brasil a incineração é utilizada apenas para resolver o problema de deposição dos resíduos perigosos e não há incineração para fins energéticos, pois para esse fim, seriam necessários aprimora- mentos a fim de se tornar ambiental e economicamente viável.

\section{Material e métodos}

\section{Local da pesquisa}

A pesquisa foi realizada no Município de Varzelândia, que se localiza a $15^{\circ} 42^{\prime} 03^{\prime \prime} \mathrm{S} \quad 44^{\circ} 01^{\prime} 40^{\prime \prime} \mathrm{O}$, com altitude de $761 \mathrm{~m}$. Segundo o IBGE (2016), a população é estimada em 19.712 habitantes, possuindo uma área de unidade territorial de $814,994 \mathrm{~km}^{2}$.

\section{Metodologia}

Para realização da pesquisa, foi utilizada a metodologia da amostragem intencional. Segundo Richardson (2007) a amostra intencional é representativa do universo pesquisado posto que os sujeitos-tipo (aqueles que representam a característica típica da população) possuem algo em comum. Nesse sentido, foi aplicado um questionário semiestruturado na prefeitura de Varzelândia sobre o gerenciamento dos resíduos sólidos na zona urbana do município e outro aos moradores para verificar algumas informações sobre os resíduos sólidos.

Ao todo, foram aplicados 200 questionários na cidade, sendo 40 para cada uma das regiões (norte, sul, leste, oeste e central). A opção de aplicar um número igual de questionários por região deve-se ao fato de que, segundo informações do próprio município, a população se distribui de forma relativamente homogênea na cidade.

Neste sentido, em ruas distintas e não muito próximas umas das outras, os moradores foram inquiridos quanto ao tema proposto. Além disso, para uma maior representatividade amostral, foram pesquisados domicílios durante $o$ dia e também à noite.

Os dados foram tabulados no SPSS, versão 18.0. Para análise e interpretação dos dados, tanto na perspectiva univariada quanto bivariada (cruzamento de variáveis), foi utilizada estatística descritiva para comparar os 
resultados coletados e verificar possíveis convergências e ou divergências entre o que afirma a gestão municipal e a população.

\section{Resultados e discussão}

Após a aplicação do questionário aos moradores, foram obtidos dados sócio demográficos da população de Varzelândia, indicados na tabela 1 . Através dos resultados apresentados, foi possível notar que $29 \%$ da população entrevistada possuem ensino médio completo e apenas 5\% possuem ensino superior completo; $12 \%$ não é alfabetizada, 29,5\% possui fundamental incompleto, 3,5\% fundamental completo e $18,5 \%$ possuem completo ensino médio incompleto.
Desta forma foi relacionado esses níveis de escolaridade à renda da população, visto que $44 \%$ dos entrevistados recebem um salário mínimo e $21 \%$ menos de um salário mínimo. A baixa renda pode ser decorrente da falta da integralização da educação básica e $63,5 \%$ da população não finalizaram a educação básica (que é compreendida como o término do ensino fundamental e médio completamente), a qual no geral é concluída até os 18 anos. E tal fato causa estranheza já que a maior parte dos entrevistados tem idade superior a 18 anos.

Os resultados sociodemográficos apresentados na Tabela 1 da população de Varzelândia podem ser resumidos na Figura 1.

Tabela 1. Variáveis sociodemográficas da população de Varzelândia/MG - 2017.

\begin{tabular}{|c|c|c|c|}
\hline Variáveis & Categorias & Quantidade & Percentual \\
\hline \multirow[t]{3}{*}{ Sexo } & Masculino & 54 & $27,0 \%$ \\
\hline & Feminino & 146 & $73,0 \%$ \\
\hline & Total & 200 & $100,0 \%$ \\
\hline \multirow[t]{6}{*}{ Faixa etária } & 16 a 20 anos & 20 & $10,0 \%$ \\
\hline & Mais de 20 a 25 anos & 16 & $8,0 \%$ \\
\hline & Mais de 25 a 30 anos & 35 & $17,5 \%$ \\
\hline & Mais de 30 a 50 anos & 69 & $34,5 \%$ \\
\hline & Acima de 50 anos & 60 & $30,0 \%$ \\
\hline & Total & 200 & $100,0 \%$ \\
\hline \multirow[t]{8}{*}{ Escolaridade } & Não alfabetizado & 24 & $12,0 \%$ \\
\hline & Ensino fundamental incompleto & 59 & $29,5 \%$ \\
\hline & Ensino fundamental completo & 07 & $3,5 \%$ \\
\hline & Ensino médio incompleto & 37 & $18,5 \%$ \\
\hline & Ensino médio completo & 58 & $29,0 \%$ \\
\hline & Ensino superior incompleto & 05 & $2,5 \%$ \\
\hline & Ensino superior completo & 10 & $5,0 \%$ \\
\hline & Total & 200 & $100,0 \%$ \\
\hline \multirow[t]{7}{*}{ Renda familiar em SM* } & Menos de um & 42 & $21,0 \%$ \\
\hline & $\mathrm{Um}$ & 88 & $44,0 \%$ \\
\hline & Mais de um a dois & 41 & $20,5 \%$ \\
\hline & Mais de dois a quatro & 06 & $3,0 \%$ \\
\hline & Mais de quatro & 03 & $1,5 \%$ \\
\hline & Não sabe & 20 & $10,0 \%$ \\
\hline & Total & 200 & $100,0 \%$ \\
\hline
\end{tabular}

*SM = Salários Mínimos 


\section{Dados sociodemográficos}

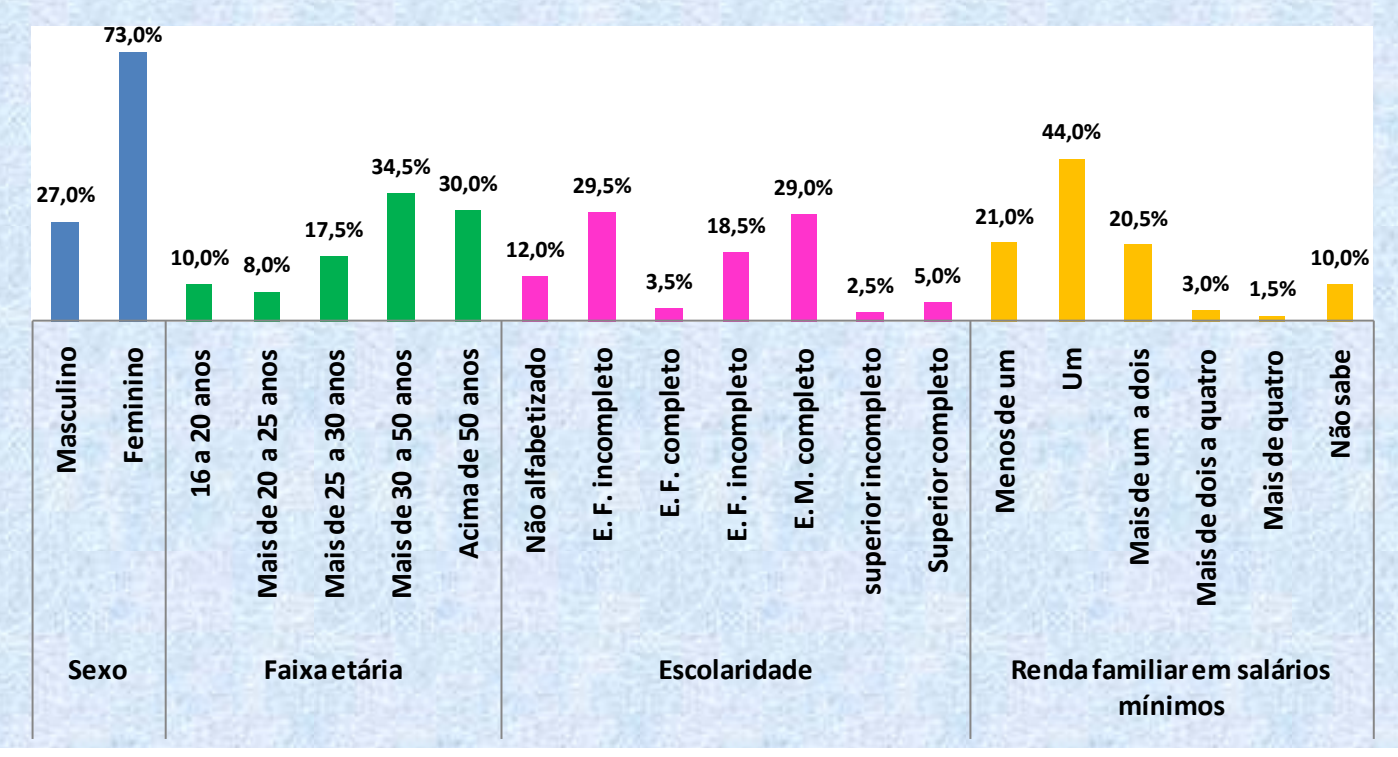

Figura 1. Dados sociodemográficos da população de Varzelândia-MG-2017.

Os resultados apresentados na Tabela 2 mostram as informações sobre o resíduos sólido de acordo a população de Varzelândia, considerando apenas a zona urbana do município. As informações são importantes para análise da gestão dos RSU do ponto de vista popular. As informações da tabela são transcritas também na forma de gráfico para melhor visualização.

Conforme dados apresentados na Tabela 2, podemos verificar que há coleta de resíduo sólido na zona urbana do município de Varzelândia, visto que $97,5 \%$ da população responderam sim para a variável coleta de lixo.

Essa informação é confirmada pelo gestor municipal, que também respondeu um questionário com essa variável. Segundo informação fornecida por ele, o resíduo sólido tem como destino o aterro sanitário e há coleta seletiva e reciclagem. Entretanto, 59\% da população não sabe qual o destino do RSU coletado na cidade e $16,5 \%$ da população não sabe o que é reciclagem. Do total dos domicílios pesquisados, $64 \%$ dos entrevistados disseram haver catadores de latas e plásticos. A presença de catadores, pode estar relacionada ao desemprego na cidade. Tal fato diverge das afirmações de Godecke et al. (2012), que como já citado, relacionam a maior produção de resíduo sólido com disposição para o consumo ou maior nível de riqueza, pois a maior parte da população da região em estudo possuem a renda familiar de um salário mínimo ou menos de um salário mínimo, sendo $41,0 \%$ um salário mínimo e 21,0\% menos de um (Figura 1). 
Tabela 2. Informaç̧ões sobre o resíduo sólido conforme população - Varzelândia/MG-2017.

\begin{tabular}{|c|c|c|c|}
\hline Variáveis & Categorias & Quantidade & Percentual \\
\hline \multirow[t]{3}{*}{ Há coleta de lixo } & Sim & 195 & $97,5 \%$ \\
\hline & Não & 5 & $2,5 \%$ \\
\hline & Total & 200 & $100,0 \%$ \\
\hline \multirow[t]{6}{*}{ Coleta semanal de lixo } & Uma vez & 52 & $26,0 \%$ \\
\hline & Duas vezes & 76 & $38,0 \%$ \\
\hline & Três vezes & 50 & $25,0 \%$ \\
\hline & Não sabe & 17 & $8,5 \%$ \\
\hline & Não há coleta & 5 & $2,5 \%$ \\
\hline & Total & 200 & $100,0 \%$ \\
\hline \multirow[t]{6}{*}{ Veículo utilizado na coleta } & Caminhão aberto & 46 & $23,0 \%$ \\
\hline & Trator com reboque & 139 & $69,5 \%$ \\
\hline & Outro & 6 & $3,0 \%$ \\
\hline & Não sabe & 4 & $2,0 \%$ \\
\hline & Não há coleta & 5 & $2,5 \%$ \\
\hline & Total & 200 & $100,0 \%$ \\
\hline Variáveis & Categorias & Quantidade & Percentual \\
\hline \multirow[t]{3}{*}{ Sabe o destino do lixo } & Sim & 82 & $41,0 \%$ \\
\hline & Não & 118 & $59,0 \%$ \\
\hline & Total & 200 & $100,0 \%$ \\
\hline \multirow[t]{4}{*}{ Sabe o que é reciclagem } & Sim, plenamente & 64 & $32,0 \%$ \\
\hline & Sim, parcialmente & 103 & $51,5 \%$ \\
\hline & Não & 33 & $16,5 \%$ \\
\hline & Total & 200 & $100,0 \%$ \\
\hline \multirow[t]{4}{*}{ Há catadores na região } & Sim & 128 & $64,0 \%$ \\
\hline & Não & 57 & $28,5 \%$ \\
\hline & Não sabe & 15 & $7,5 \%$ \\
\hline & Total & 200 & $100,0 \%$ \\
\hline \multirow[t]{5}{*}{ № de dias de varrição de rua } & Nenhum & 92 & $46,0 \%$ \\
\hline & Um dia & 23 & $11,5 \%$ \\
\hline & Dois ou mais & 58 & $29,0 \%$ \\
\hline & Não sabe & 27 & $13,5 \%$ \\
\hline & Total & 200 & $100,0 \%$ \\
\hline
\end{tabular}

Apesar de 38,0\% da população responderem que há coleta de resíduo sólido duas vezes semanal e $25,0 \%$ três vezes por semana, é curioso observar que há um percentual considerável $(46,0 \%)$ que responderam que não há serviço de varrição de rua. Ou seja, é possível inferir que, embora haja a coleta, os serviços prestados pelo município são parciais. Isso é fator de preocupação, pois a não variação de rua pode trazer danos prejudiciais à população. Essas informações foram reproduzidas na Figura 2 para melhor visualização. 


\section{Informações sobre o lixo}

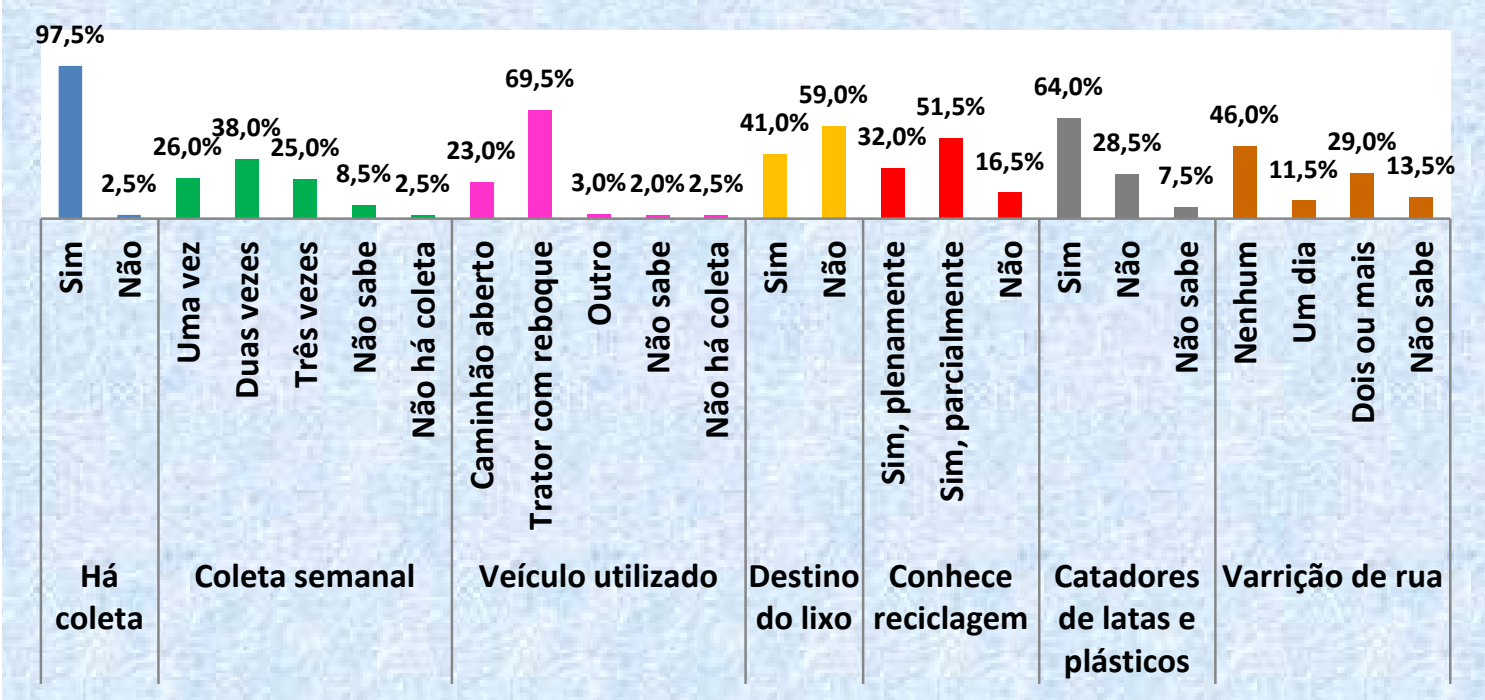

Figura 2. Informações sobre o resíduo sólido conforme população - Varzelândia/MG - 2017.

Um dos objetivos da Política Nacional do Meio Ambiente é: "educação ambiental a todos os níveis de ensino, inclusive a educação da comunidade, objetivando capacitá-la para participação ativa na defesa do meio ambiente." E um dos princípios da Política Nacional do
Meio Ambiente é a não geração, redução, reutilização, reciclagem e tratamento dos resíduos sólidos. Nesse contexto entra a educação ambiental, fundamental para atender esses objetivos na gestão de resíduos sólidos.

Tabela 3. Variáveis sobre projeto ambiental e reclamações - Varzelândia/MG - 2017.

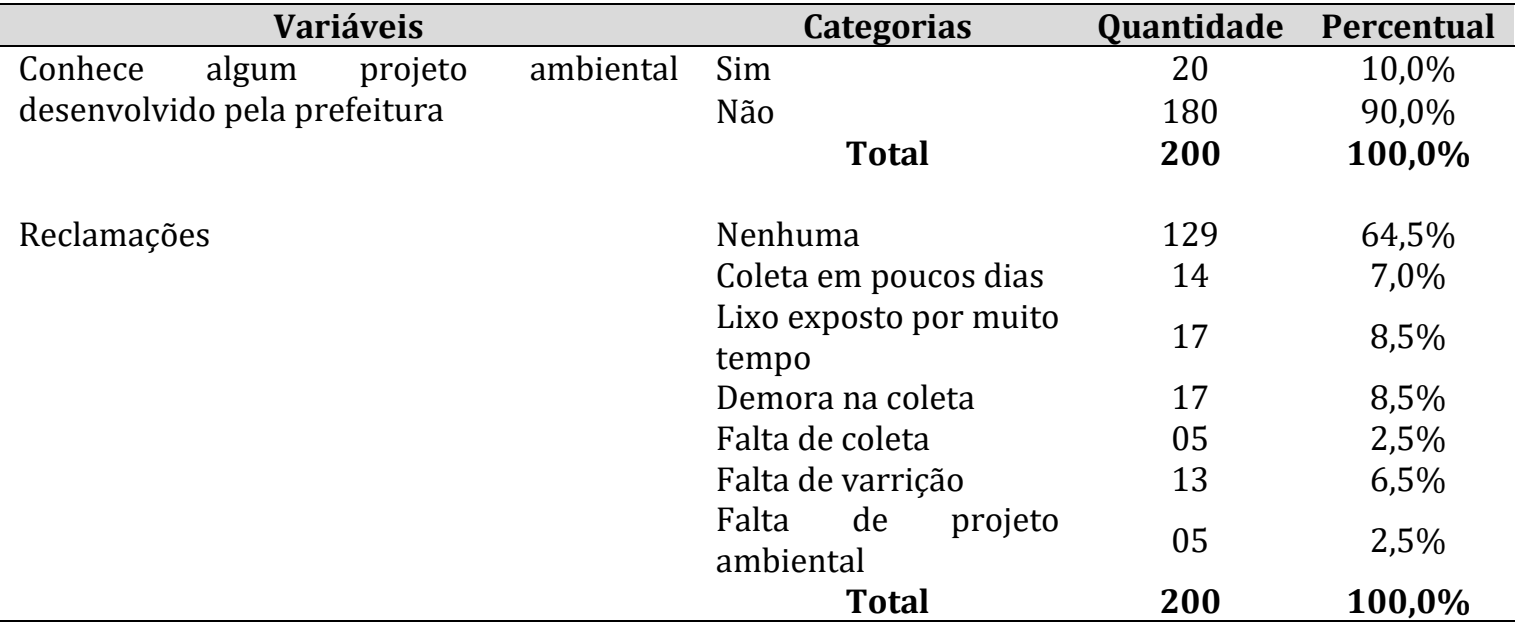

Fonte: Dados coletados pela autora.

De acordo as informações prestadas pela população entrevistada, a Tabela 3 mostra que $90,0 \%$ não conhecem projeto ambiental desenvolvido pela Prefeitura de Varzelândia e essa resposta é 
corroborada pelo gestor municipal que informa que não há de fato projeto ambiental executado pela prefeitura.

No questionário aplicado ao gestor municipal dos RSU, foi perguntado se o mesmo conhece as normas e legislação sobre os resíduos sólidos e a resposta foi que há um conhecimento parcial. Cabe indagar o motivo pelo qual na gestão dos RSU não há projeto ambiental desenvolvido pela prefeitura, já que o gestor tem um conhecimento mesmo que parcial sobre a legislação dos resíduos sólidos. Seria importante executar um projeto ambiental para que a população obtenha maiores esclarecimentos sobre como colaborar com o meio ambiente. No caso dos RSU, a reciclagem seria uma forma de preservar os recursos naturais, pois, reduziria a quantidade de resíduo sólido. A conscientização ambiental se torna importante na área de estudo visto que $16,5 \%$ da população entrevistada não sabem o que é reciclagem e 16, $5 \%$ sabem, porém, parcialmente (Tabela 2).
0 gestor informa que existe no município o Plano Municipal de Gestão Integrada de Resíduos Sólidos (PMGURS), aprovado por lei municipal. Esta informação é bem procedente, visto que a Lei no 12.305/2010 (Brasil, 2010), em seu artigo 18, estabelece que "a elaboração de plano municipal de gestão integrada de resíduos sólidos, [...] é condição para o Distrito Federal e os Municípios terem acesso a recursos da União, ou por ela controlados, destinados a empreendimentos e serviços relacionados à limpeza urbana e ao manejo de resíduos sólidos.

0 gestor municipal considera a PNRS bem executada, em sua totalidade, no Município. Entretanto, 35,5\% da população apontaram algum tipo de reclamação no que se refere aos RSU. Os percentuais de cada reclamação estão na Tabela 3 e foram transcritas para a Figura 3, onde estão visíveis os percentuais de cada reclamação.

Figura 3. Conhecimento sobre algum projeto ambiental desenvolvido pela prefeitura e principais reclamações apontadas pela população - Varzelândia/MG -2017.

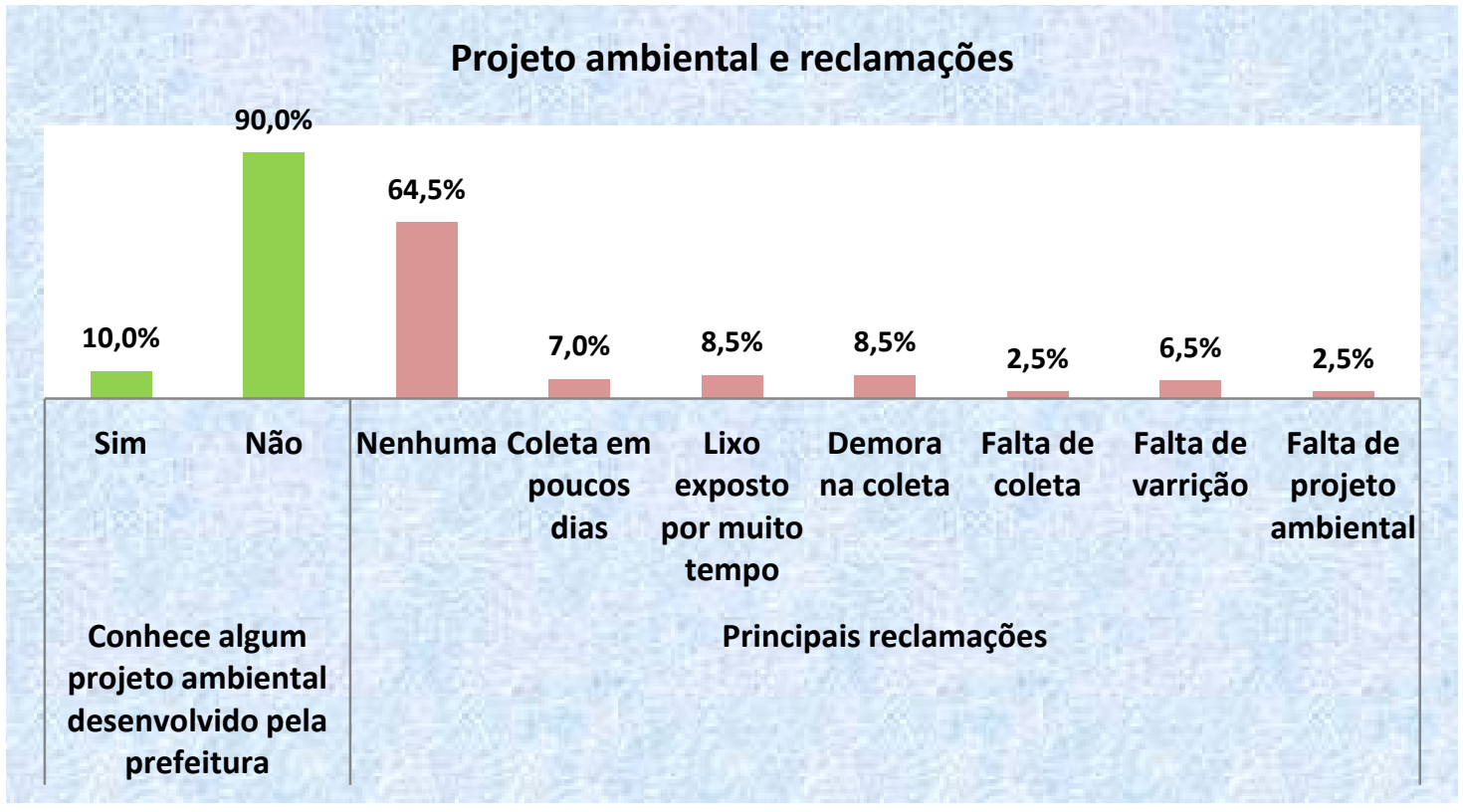


A análise bivariada busca estabelecer relações entre as variáveis, onde é possível estabelecer comparações entre elas. Na Tabela 4, é estabelecida a relação de escolaridade versus conhecimento sobre destinação do lixo.

Tabela 4. Escolaridade x tem conhecimento sobre o destino do resíduo sólido * - Varzelândia/MG 2017.

\begin{tabular}{|c|c|c|c|}
\hline \multirow{2}{*}{ Escolaridade } & \multicolumn{2}{|c|}{ Conhecimento sobre o destino do lixo } & \multirow{2}{*}{ Total } \\
\hline & Sim & Não & \\
\hline \multirow{2}{*}{ Não alfabetizado } & 5 & 19 & 24 \\
\hline & $20,8 \%$ & $79,2 \%$ & $100,0 \%$ \\
\hline \multirow{2}{*}{ E. F. incompleto } & 19 & 40 & 59 \\
\hline & $32,2 \%$ & $67,8 \%$ & $100,0 \%$ \\
\hline \multirow{2}{*}{ E. F. completo } & 3 & 4 & 7 \\
\hline & $42,9 \%$ & $57,1 \%$ & $100,0 \%$ \\
\hline \multirow{2}{*}{ E. M. incompleto } & 20 & 17 & 37 \\
\hline & $54,1 \%$ & $45,9 \%$ & $100,0 \%$ \\
\hline \multirow{2}{*}{ E. M. completo } & 26 & 32 & 58 \\
\hline & $44,8 \%$ & $55,2 \%$ & $100,0 \%$ \\
\hline \multirow{2}{*}{ Superior incompleto } & 3 & 2 & 5 \\
\hline & $60,0 \%$ & $40,0 \%$ & $100,0 \%$ \\
\hline \multirow{2}{*}{ Superior completo } & 6 & 4 & 10 \\
\hline & $60,0 \%$ & $40,0 \%$ & $100,0 \%$ \\
\hline \multirow{2}{*}{ Total } & 82 & 118 & 200 \\
\hline & $41,0 \%$ & $59,0 \%$ & $100,0 \%$ \\
\hline
\end{tabular}

*Percentagens relativas ao total da linha.

Na Tabela 4, que relaciona o nível de escolaridade com o conhecimento sobre a destinação do resíduo sólido, é curioso atentar para o fato deque boa parte da população entrevistada desconhece qual o destino do lixo, em todos os níveis de escolaridade. Como o nível superior normalmente possui um conhecimento mais aprofundado, causa estranheza que dos moradores que possuem curso superior completo $40 \%$ deles desconhecem a destinação do RSU.

A Tabela 5 compara o nível de escolaridade com o conhecimento sobre a reciclagem. Os resultados apresentados nesta tabela evidenciam, com bastante notoriedade, que dos entrevistados com ensino superior completo ou incompleto tem algum conhecimento sobre reciclagem, seja parcial ou plenamente, $\mathrm{o}$ que não ocorre nos demais níveis escolares. Dos não alfabetizados, 58,3\% não sabem o que é reciclagem e $20,3 \%$ dos que possuem ensino fundamental incompleto também não sabem o que é reciclagem.

A Tabela 6 relaciona varrição de rua com reclamações dos moradores e também com a região de aplicação dos questionários. 0 objetivo do cruzamento entre essas variáveis é verificar se a varrição de rua é apontada como a principal reclamação pelos moradores das diferentes regiões, já que o gestor informou que esta é a principal reclamação da população, acrescentando que este serviço é ausente em alguns bairros. Além disso, o cruzamento dessas variáveis irá ajudar na análise da gestão de RSU a fim de verificar se a mesma ocorre da mesma forma em todas as regiões da cidade (norte, sul, leste, oeste e centro), de acordo a opinião dos moradores. Caso não haja reclamações, é possível considerar que a população está satisfeita com a gestão de RSU. Se a população não tiver reclamações, podemos considerar coerente com a 
pinião do gestor que afirma que considera que a Política Nacional dos
Resíduos Sólidos é bem executada no município, em sua totalidade.

Tabela 5. Escolaridade x sabe o que é reciclagem* - Varzelândia/MG - 2017.

\begin{tabular}{|c|c|c|c|c|}
\hline \multirow{2}{*}{ Escolaridade } & \multicolumn{3}{|c|}{ Sabe o que é reciclagem } & \multirow{2}{*}{ Total } \\
\hline & Sim, plenamente & Sim, parcialmente & Não & \\
\hline \multirow[t]{2}{*}{ Não alfabetizado } & 2 & 8 & 14 & 24 \\
\hline & $8,3 \%$ & $33,3 \%$ & $58,3 \%$ & $100,0 \%$ \\
\hline \multirow[t]{2}{*}{ E. F. incompleto } & 18 & 29 & 12 & 59 \\
\hline & $30,5 \%$ & $49,2 \%$ & $20,3 \%$ & $100,0 \%$ \\
\hline \multirow[t]{2}{*}{ E. F. completo } & 4 & 3 & 0 & 7 \\
\hline & $57,1 \%$ & $42,9 \%$ & $0,0 \%$ & $100,0 \%$ \\
\hline \multirow{2}{*}{ Escolaridade } & \multicolumn{3}{|c|}{ Sabe o que é reciclagem } & \multirow{2}{*}{ Total } \\
\hline & Sim, plenamente & Sim, parcialmente & Não & \\
\hline \multirow[t]{2}{*}{ E. M. incompleto } & 6 & 28 & 3 & 37 \\
\hline & $16,2 \%$ & $75,7 \%$ & $8,1 \%$ & $100,0 \%$ \\
\hline \multirow[t]{2}{*}{ E. M. completo } & 26 & 28 & 4 & 58 \\
\hline & $44,8 \%$ & $48,3 \%$ & $6,9 \%$ & $100,0 \%$ \\
\hline \multirow[t]{2}{*}{ Superior incompleto } & 3 & 2 & 0 & 5 \\
\hline & $60,0 \%$ & $40,0 \%$ & $0,0 \%$ & $100,0 \%$ \\
\hline \multirow[t]{2}{*}{ Superior completo } & 5 & 5 & 0 & 10 \\
\hline & $50,0 \%$ & $50,0 \%$ & $0,0 \%$ & $100,0 \%$ \\
\hline \multirow{2}{*}{ Total } & 64 & 103 & 33 & 200 \\
\hline & $32,0 \%$ & $51,5 \%$ & $16,5 \%$ & $100,0 \%$ \\
\hline
\end{tabular}

Fonte: Dados coletados pela autora (2017). Nota: *Percentagens relativas ao total da linha.

Pelos resultados apresentados, tem-se que dos entrevistados na região leste $80,0 \%$ deles responderam que não há varrição de rua, na Região Oeste e Sul também há um percentual considerável de pessoas que responderam que não há varrição de rua, sendo que foram entrevistadas 40 pessoas em cada região e os percentuais por região que responderam que não há varrição de rua foi $62,5 \%$ na Região Oeste e $62,5 \%$ na região Sul. Sendo assim, esses resultados corroboram com a opinião do gestor. Tais resultados podem estar relacionados com o fato de essas regiões terem uma maior quantidade de ruas não asfaltadas, diferentemente da região do centro e da região norte, onde há varrição de dois dias ou mais, de acordo $65,0 \%$ e $50 \%$, respectivamente, dos entrevistados.

Quanto ao cruzamento das variáveis reclamação e varrição de rua, os resultados presentes na Tabela 6 mostram certa coerência, pois dos entrevistados que responderam que não há varrição de rua, 76,9\% deles tiveram reclamação sobre este serviço. Dos entrevistados que responderam que não há varrição de rua, $100 \%$ deles reclamaram que não há coleta. Um fato interessante é que dos resultados acima é curioso notar que dentre os entrevistados que reclamaram da falta de varrição de rua, 23, 1\% deles não sabem quantos dias a rua é varrida. 
Tabela 6. Varrição de rua x região e reclamações dos moradores* - Varzelândia/MG - 2017.

\begin{tabular}{|c|c|c|c|c|c|}
\hline \multirow{2}{*}{ Região } & \multicolumn{4}{|c|}{ Número de dias semanais de varrição de rua } & \multirow{2}{*}{ Total } \\
\hline & Nenhum & Um dia & Dois ou mais & Não sabe & \\
\hline \multirow[t]{2}{*}{ Norte } & 6 & 2 & 26 & 6 & 40 \\
\hline & $15,0 \%$ & $5,0 \%$ & $65,0 \%$ & $15,0 \%$ & $100,0 \%$ \\
\hline \multirow[t]{2}{*}{ Sul } & 25 & 4 & 7 & 4 & 40 \\
\hline & $62,5 \%$ & $10,0 \%$ & $17,5 \%$ & $10,0 \%$ & $100,0 \%$ \\
\hline \multirow[t]{2}{*}{ Leste } & 32 & 1 & 2 & 5 & 40 \\
\hline & $80,0 \%$ & $2,5 \%$ & $5,0 \%$ & $12,5 \%$ & $100,0 \%$ \\
\hline \multirow{2}{*}{ Região } & \multicolumn{4}{|c|}{ Número de dias semanais de varrição de rua } & Total \\
\hline & Nenhum & Um dia & Dois ou mais & Não sabe & \\
\hline \multirow[t]{2}{*}{ Oeste } & 25 & 9 & 3 & 3 & 40 \\
\hline & $62,5 \%$ & $22,5 \%$ & $7,5 \%$ & $7,5 \%$ & $100,0 \%$ \\
\hline \multirow[t]{2}{*}{ Centro } & 4 & 7 & 20 & 9 & 40 \\
\hline & $10,0 \%$ & $17,5 \%$ & $50,0 \%$ & $22,5 \%$ & $100,0 \%$ \\
\hline \multirow{2}{*}{ Total } & 92 & 23 & 58 & 27 & 200 \\
\hline & $46,0 \%$ & $11,5 \%$ & $29,0 \%$ & $13,5 \%$ & $100,0 \%$ \\
\hline \multirow{2}{*}{ Reclamações } & \multicolumn{4}{|c|}{ Número de dias semanais de varrição de rua } & Total \\
\hline & Nenhum & Um dia & Dois ou mais & Não sabe & \\
\hline \multirow[t]{2}{*}{ Nenhuma } & 48 & 16 & 49 & 16 & 129 \\
\hline & $37,2 \%$ & $12,4 \%$ & $38,0 \%$ & $12,4 \%$ & $100,0 \%$ \\
\hline \multirow[t]{2}{*}{ Coleta em poucos dias } & 7 & 4 & 2 & 1 & 14 \\
\hline & $50,0 \%$ & $28,6 \%$ & $14,3 \%$ & $7,1 \%$ & $100,0 \%$ \\
\hline \multirow[t]{2}{*}{ Lixo exposto por muito tempo } & 6 & 2 & 4 & 5 & 17 \\
\hline & $35,3 \%$ & $11,8 \%$ & $23,5 \%$ & $29,4 \%$ & $100,0 \%$ \\
\hline \multirow[t]{2}{*}{ Demora na coleta } & 13 & 1 & 2 & 1 & 17 \\
\hline & $76,5 \%$ & $5,9 \%$ & $11,8 \%$ & $5,9 \%$ & $100,0 \%$ \\
\hline \multirow[t]{2}{*}{ Falta de coleta } & 5 & 0 & 0 & 0 & 5 \\
\hline & $100,0 \%$ & $0,0 \%$ & $0,0 \%$ & $0,0 \%$ & $100,0 \%$ \\
\hline \multirow[t]{2}{*}{ Falta de varrição } & 10 & 0 & 0 & 3 & 13 \\
\hline & $76,9 \%$ & $0,0 \%$ & $0,0 \%$ & $23,1 \%$ & $100,0 \%$ \\
\hline \multirow[t]{2}{*}{ Falta de projeto ambiental } & 3 & 0 & 1 & 1 & 5 \\
\hline & $60,0 \%$ & $0,0 \%$ & $20,0 \%$ & $20,0 \%$ & $100,0 \%$ \\
\hline \multirow{2}{*}{ Total } & 92 & 23 & 58 & 27 & 200 \\
\hline & $46,0 \%$ & $11,5 \%$ & $29,0 \%$ & $13,5 \%$ & $100,0 \%$ \\
\hline
\end{tabular}

*Percentagens relativas ao total da linha.

\section{Conclusão}

Pelos resultados apresentados durante o trabalho, podemos considerar que a gestão de resíduos sólidos urbanos (RSU) no Município de Varzelândia, do ponto de vista da população é bem executada, já que $64,5 \%$ não apresentaram nenhum tipo de reclamação acerca desse gerenciamento. A boa execução da gestão dos RSU também é confirmada com a opinião do gestor municipal. A prefeitura não desenvolve nenhum projeto ambiental a fim de conscientizar a população.

De fato, $90,0 \%$ da população entrevistada não conhece nenhum projeto ambiental. Entretanto, $10 \%$ da população informam que conhece algum projeto ambiental desenvolvido e tal resposta pode ter ocorrido talvez pelo fato da pessoa não compreender o que seja projeto ambiental. Um dos pontos solicitados pela Política Nacional do Meio Ambienta (PNMA) é a educação ambiental em todos os níveis de 
escolaridade e isso não ocorre na gestão de RSU em Varzelândia.

Quando se observa que 64,5\% dos entrevistados não tinham nenhum tipo de reclamação quanto aos serviços prestados pelo município, possivelmente o desconhecimento sobre as políticas ambientais e de resíduos sólidos sejam um dos motivos pelos quais os moradores não apontem reclamações.

As demais reclamações existentes talvez não seja passada ao gestor, já que o mesmo informou que a principal reclamação era a falta de varrição de rua. O município possui o plano de gestão integrada de resíduos sólidos, pois é fator fundamental para receber recursos da União.

A população em geral possui um baixo nível de escolaridade e baixa renda e esses dois fatores estão correlacionados. Mesmo na população com nível superior há desconhecimento quanto à destinação do lixo. Sendo assim, as informações do gestor e população são coerentes entre si. A gestão de acordo a população e o gestor é eficiente, pois para o gestor está sendo bem executada no município e a maior parte da população não tem nenhum tipo de reclamação, o que pode ser considerado um nível satisfatório. No município há reciclagem, porém, verificou-se a ausência de projetos de educação ambiental, os quais se utilizados, poderiam auxiliar na colaboração e conscientização por parte da população.

\section{Declaração de conflito de interesses}

Os autores declaram não haver conflito de interesses.

\section{Referências}

Barros, R. M. Tratado sobre resíduos sólidos: gestão, uso e sustentabilidade. Rio de Janeiro: Interciência, 2013.

Bartholomeu, D. B.; Caixeta-Filho, J. V. (Org.). Logística ambiental de resíduos sólidos. São Paulo: Atlas, 2011.
Brasil. Lei no 6.938, de 31 de agosto de 1981. Dispõe sobre a Política Nacional do Meio Ambiente (PNMA), seus fins e mecanismos de formulação e aplicação, e dá outras providências. Disponível em: <http://www.planalto.gov.br/ccivil_03/leis/ L6938.htm>. Acesso em: 29 mar. 2017.

Brasil. Lei no 12.305, de 2 de agosto de 2010. Institui a Política Nacional de Resíduos Sólidos; altera a Lei no 9.605, de 12 de fevereiro de 1998; e dá outras providências. Disponível em: <http://www.planalto. gov.br/ccivil_03/_ato2007-

2010/2010/lei/l12305.htm>. Acesso em: 29 maio 2017.

CMMAD - Comissão Mundial sobre Meio Ambiente e Desenvolvimento. Nosso futuro comum. 2. ed. Rio de Janeiro, Editora FGV, 1991.

Godecke, M. V.; Naime, R. H.; Figueiredo, J. A. S. O consumismo e a geração de resíduos sólidos no Brasil. Revista Eletrônica em Gestão, Educação e Tecnologia Ambiental, v. $8, \quad$ n. $8, \quad$ p. $1700-1712,2012$. https://doi.org/10.5902/223611706380

Henriques, R. M. Aproveitamento energético dos resíduos sólidos urbanos: uma abordagem tecnológica. Rio de Janeiro: COPPE/UFRJ, 2004. (Dissertação de mestrado).

IEA - International Anergy Agency. Renewables in power generation: towards a better environment. Paris: IEA, 1997.

IBGE - Instituto Brasileiro de Geografia e Estatística. 2016. Disponível em: <http://cidades.ibge.gov.br/xtras/perfil.php? lang $=\&$ codmun $=317090 \&$ search $=$ minasgerai s|varzelandia>. Acesso em: 04 mar. 2017.

Jacobi, P. R.; Besen, G. R. Gestão de resíduos sólidos na região metropolitana de São Paulo avanços e desafios. Revista São Paulo em Perspectiva, v. 20, n. 2, p. 90-104, 2006. Disponível em: <http://produtos.seade. gov.br/produtos/spp/v20n02/v20n02_07.pd f>. Acesso em: 04 mar.2017.

Jacobi, P. R.; Besen, G. R. Gestão de resíduos sólidos em São Paulo: desafios da sustentabilidade. Estudos Avançados, v. 25, n. 71, p. 135-158, 2011. https://doi.org/ 10.1590/S0103-40142011000100010

Nogueira, M. D. P. Knauer, L. G.; Henriques, M. S.; Nogueira, A. B. Lixo e cidadania: uma experiência inovadora no médio vale do Jequitinhonha-MG. Belo Horizonte: PROEX/UFMG, 2007. 
Richardson, R. J. Pesquisa social: métodos e técnicas. 3. ed. São Paulo: Atlas, 2007.

Russo, M. A. T. Tratamento de resíduos sólidos. Coimbra: Universidade de Coimbra, 2003. Disponível em: <http://www1.ci.uc.pt/ mhidro/edicoes_antigas/Tratamentos_Resid uos_Solidos.pdf>. Acesso em: 27 maio 2017.

Zveibil, V. Z. Manual de Gerenciamento Integrado de resíduos sólidos. Rio de Janeiro: IBAM, 2001. Disponível em: $<$ http://www.resol.com.br/cartilha4/manual .pdf>. Acesso em: 29 maio 2017. seja devidamente citada. 